\title{
ARTICLE
}

\section{An In-depth Analysis for Optimal Cable Tray Support Span}

\author{
Sung Wuk Jung Erkan Oterkus* \\ University of Strathclyde, United Kingdom
}

\section{ARTICLE INFO}

Article history

Received: 7 January 2021

Accepted: 29 January 2021

Published Online: 31 January 2021

\section{Keywords:}

Cable tray system

Finite element method

ANSYS

Oil and gas

Offshore

\begin{abstract}
Nowadays, it is crucial to reduce the cost of the overall project so that the competitiveness of offshore oil and gas without compromising on quality or safety can be achieved. This study investigates how to define the longest cable tray support span considering constructability in order to reduce the number of supports which is a chief cost of a cable tray system. This study presents not only material and geometry frequently used for cable tray but also the formula to estimate the maximum cable load which can be installed within cable tray. To verify the longest span without increasing the crosssection of cable tray, finite element modelling approach was employed based on ANSYS and comparisons were made between numerical analysis and simplified hand calculation. The constructability for the longer span obtained from finite element analysis has been validated in view of manual handling of the cable tray. It is shown that the optimal span suggested in this paper can lead to a better economic benefit without degrading the constructability. For instance, as the span is longer, the cost of material as well as construction manpower can be saved. It is also expected that this approach will contribute to enhance the competitiveness of offshore oil and gas.
\end{abstract}

Joint Industry Project (JIP) was established with various participants such as HHI, DSME, BV, ABS, DNV-GL, Chevron, TechnipFMC and others to reduce cost and increase predictability in international offshore EPC projects by using standardized materials, design and procedures for construction and commissioning in $2015^{[2]}$.

A cable tray system is used to support the insulated electrical cable used for power distribution, control and communication in the electrical wiring. Cable tray system has various shapes and sizes in the market. In the design of a cable tray, the most significant cost driver is the cost of the supports. The number of structural steel supports needed in cable tray installation is mainly determined by the support span. Typically, $3 \mathrm{~m}$ is the maximum support

*Corresponding Author:

Erkan Oterkus,

University of Strathclyde, United Kingdom;

Email: erkan.oterkus@strath.ac.uk 
span employed in offshore oil and gas. However, total installed cost for cable tray can be lower if a longer span than industrial practice is utilized in offshore industry.

The simplest way to achieve the longer span is to enhance the cross-section of cable tray. Recently, there were several trials to employ the longer span with thicker cable tray in offshore industry to reduce the overall cost. Despite the cost savings, there are also the negative points caused by the heavier cable tray at longer span. For instance, if the weight of cable tray remarkably increases at longer span, it will cause difficulty in cable tray handling and installation. It is the main reason that more than $3 \mathrm{~m}$ span length is not generally applied to offshore industry.

Although 3 meter is the commonly employed support span for cable ladder horizontal run in offshore oil and gas industry, it is required to study whether longer span can be utilized without degrading the constructability. To achieve it, first, the maximum cable weight allowed by cable ladder space needs to be defined then the longest span which can meet both NEMA VE 1and IEC 61537 under the largest load condition shall be evaluated in the view of constructability.

There are several standards to give suggestion for the critical bending moment of the elastic lateral torsional buckling (LTB). However, their formulas are hard to apply to find the failure load of the cable ladder.

In all equations of critical bending moment, the unbraced length of the beam is important variable to determine the $\mathrm{M}_{\mathrm{cr}}$. However, it is difficult to clearly define the unbraced length of the beam in cable ladder structure because the rung structures of cable ladder partially restrain the lateral displacement of the side rail as indicated in Figure 1.

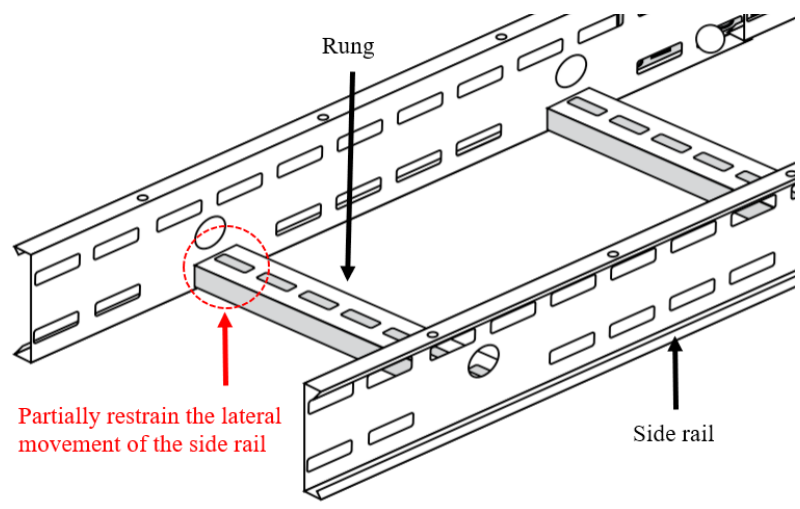

Figure 1. Partial lateral restraint of cable ladder ${ }^{[13]}$

Through finite element analysis to verify the effect of rung at bucking, it has been recognized that the shorter interval between rungs has greater eigen buckling factor (see Table 1).
Table 1. The effect of rung interval length for LTB

\begin{tabular}{ccc}
\hline Span between support & Interval of rung & $\begin{array}{c}\text { Eigen Bucking } \\
\text { factor }\end{array}$ \\
\hline $\begin{array}{c}\text { Total Span: } 3.6 \mathrm{~m} \\
\text { Load over span: } 6755 \mathrm{~N}\end{array}$ & $\begin{array}{c}\text { 300mm } \\
\text { (Total rung Qty: 12ea) }\end{array}$ & 1.2 \\
$\begin{array}{c}\text { Total Span: } 3.6 \mathrm{~m} \\
\text { Load over span: } 6755 \mathrm{~N}\end{array}$ & $\begin{array}{c}\text { (To0mm } \\
\text { (Totang Qty: 6ea) }\end{array}$ & 0.5 \\
\hline
\end{tabular}

In addition, the latest version of Eurocode 3 does not specify the method to calculate the elastic critical bending moment for the LTB of beams. The old version of Eurocode 3 named ENV 1993-1: 1992 had the 3-factor formula incorporated though, and the formula is now found in NCCI ${ }^{[3]}$. However, NCCI states the expression of Mcr only for uniform straight members that the cross section is symmetric around the minor axis.

For cases not covered by NCCI, critical moment may be determined by a buckling analysis of the beam provided that the calculation accounts for all the parameters liable to affect the value of Mcr :

(1) Geometry of the cross-section

(2) Warping rigidity

(3) Position of the transverse loading with regard to the shear centre

(4) Restraint conditions

Therefore, it is very complicated and difficult work to check the lateral torsional buckling of cable ladder structure indicated in Figure 1 via hand calculation. So, by using numerical methods for the elastic buckling solution, the elastic buckling analysis of the cable ladder needs to be performed to find the failure load of cable ladder as well as the optimal span.

There are various studies in the literature for the analysis of cable trays. Amongst these, Kalupa ${ }^{[4]}$ presented guidelines to be used in the design of cable tray systems particularly for electrical industry. Desmond and Dermitzakis ${ }^{[5]}$ provided effective-length factors for the buckling of cable-tray supports used at nuclear power facilities. Reigles et. al. ${ }^{[6]}$ presented a review of test data and conclusions to develop a design methodology for the seismic qualification of safety-related cable tray support systems. Masoni et. al. ${ }^{[7]}$ performed shaking-table tests on full-scale three dimensional cable tray systems. In another study, Huang et. al. ${ }^{[8]}$ performed shaking table tests to investigate the seismic performance and damping ratio of cable tray systems in nuclear power systems. Huang and Mosalam ${ }^{[9]}$ developed a finite element model of the cable tray for time history analysis under the effect of selected ground motions.

In this study, how much span can be longer than off- 
shore practice without increasing the cross-section of cable tray is investigated. The geometry including thickness and material which are the most often used for cable tray is described for finite element analysis (FEA) and hand calculation to verify the optimal span. It also provides a method to estimate the maximum cable weight which can be installed in a cable tray. In addition, it suggests how to determine the longest span via FEA considering constructability. Finally, it presents the positive impacts induced by the optimal span which is obtained from this study.

\section{Methodology}

To define optimal cable tray support span, this research will conduct quantitative analysis for cable tray buckling and deflection at the maximum cable load. The approach adopted is described as below:

Step 1: To define the material property and geometry for the cable tray.

Step 2: To define the criteria to determine the optimal span

Step 3: To calculate the maximum cable load

Step 4: To conduct finite element analysis

Step 5: To conduct simplified hand calculation.

Step 6: To do the verification of result.

\subsection{Step 1: Define Material Property and Geome- try}

Stainless steel ANSI 316L (EN 1.4404) ladder type is selected for this study because it is the most frequently used in offshore oil and gas industry. The mechanical properties for EN 1.4404 from British Standard European Norm is indicated in Table 2.

Table 2. The mechanical property of EN $1.4404^{[10-12]}$

\begin{tabular}{cc}
\hline Mechanical property & Value \\
\hline Poisson's ratio & 0.3 \\
Elastic modulus (GPa) & 200 \\
$\begin{array}{c}\text { Yield strength (MPa) } \\
\text { Proof strength } \\
\text { Tensile strength (MPa) }\end{array}$ & 240 \\
\hline
\end{tabular}

In general, I beam profile can carry more load than $\mathrm{C}$ channel beam profile. Therefore, $\mathrm{C}$ channel beam shape is selected for side rail of cable ladder in order to define the longest span allowed in worst condition. Figure 2 and Table 3 provides information about the product, OE 150 of Oglaend system ${ }^{[13]}$ which is one of well-known channel type products.

Table 3. The data for geometry

\begin{tabular}{cc}
\hline Geometry data & Value \\
\hline Side rail height $(\mathrm{mm})$ & 150 \\
Thickness of side rail (mm) & 1.5 \\
Rung length (mm) & 900 \\
Moment of Inertia Ixx for the side rail $\left(\mathrm{mm}^{4}\right)$ & 933,170 \\
\hline
\end{tabular}

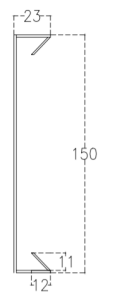

Side rail section view (Thickness: $1.5 \mathrm{~mm}$ )

Figure 2. Channel type side rail ${ }^{[13]}$

\subsection{Step 2: Define Criteria to Determine the Opti- mal Span}

There are two kinds of load test methods to verify optimal support span. One is the destruction load test at simple beam and the other is the deflection load test at continuous beam. The optimal support span shall meet both load test criteria at the greatest cable load which is defined in step 3 .

\subsubsection{NEMA VE-1 Destruction Load Test}

Figure 3 shows the NEMA VE 1 safe rated load test (destruction load test) at simple span. In this load test, both ends of straight section shall be supported directly on a $65 \mathrm{~mm}$ diameter round steel bar or heavy wall steel tube fastened to a rigid base. Then, the load which is 1.5 times (safety factor) of the maximum cable weight defined in step 3 distributed uniformly along the span. In this study, the span increases with interval of $300 \mathrm{~mm}$ until it causes the collapse ${ }^{[14]}$.

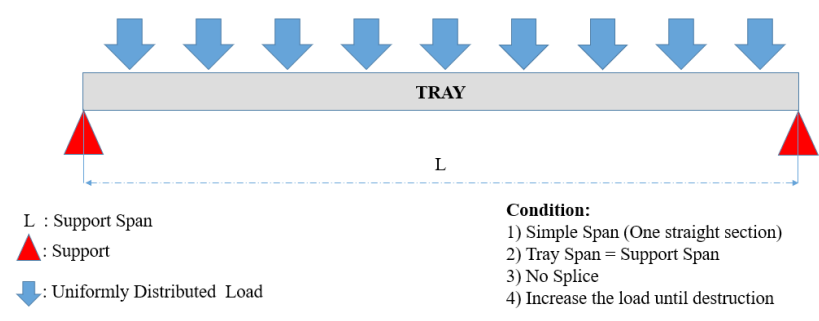

Figure 3. Safe rated load test with simple span according to NEMA VE-1 


\subsubsection{IEC 61537 Deflection Load Test}

The other method is the safety working load (deflection load) test on multiple span based on IEC 61537. The test shall be conducted with the samples consisting of two or more cable ladder lengths over multiple support span given in Figure 4. Cable ladders shall be placed on fixed, rigid supports which shall be horizontal and level with a width of $45 \mathrm{~mm} \pm 5 \mathrm{~mm}$. The ladders shall not be fixed to the supports unless a fixing method is declared by the manufacturer in which case this fixing method shall be used $^{[15]}$.

The load, 1.7 times (safety factor) of the maximum cable load, shall be uniformly distributed on end span, intermediate span and cantilever and each support and splicing(joint) shall be positioned according to Figure 4 . The vertical deflection at mid-span shall be measured at the points near the side rails and its result shall be less than $1 / 100$ of span without collapsing in order to meet the IEC criteria but buckling and deformation of the cable ladders is permissible.

The span increases with interval of $300 \mathrm{~mm}$ until the collapse is caused or the vertical deflection is more than $1 / 100$ of span.

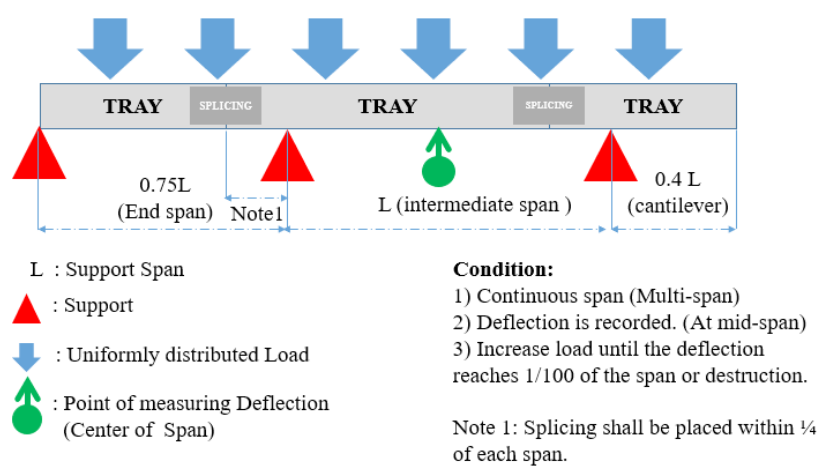

Figure 4. Deflection load test with multiple span according to IEC 61537 type test II

In addition, transverse deflection (rung sagging) is not considered in this study as it is theoretically not affected by support spacing space. Thus, transverse displacement is not discussed here.

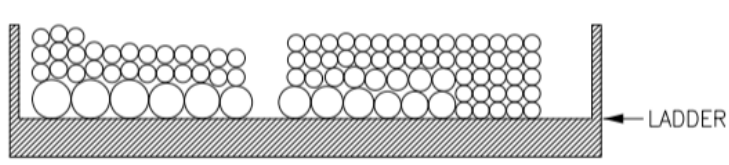

LADDER FOR CONTROL CABLES

\subsection{Step 3: Calculate Maximum Cable Load}

National Electrical Code (NEC) states the high voltage power cables shall be installed in a single layer with certain distance between two cables. However, control and communication cables which has no heat generation problem can be stacked together in several layers as long as the sum of the cross-sectional areas of all cables does not exceed $50 \%$ of fill area of the ladder ${ }^{[16]}$.

Figure 5 shows the ladder fully filled with control cables versus the ladder fully filled with high voltage cables. As indicated in Figure 5, the cross section of cable ladder can be more occupied with the cables when it is fully filled with control cables. Therefore, the largest cable weight can be estimated based on the case that the sum of control cables cross section equals to $50 \%$ of fill area of the cable ladder. Following is formula to calculate the maximum cable load depending on ladder cross section.

The largest cable load per one-meter ladder is

Max.Cable $\operatorname{Load}(\mathrm{kg} / \mathrm{m})=\mathrm{N} \times \mathrm{m}$

where

$\mathrm{N}=\frac{\Delta \mathrm{h} \times \mathrm{W} \times 0.5}{\mathrm{~A}}$

and $\Delta \mathrm{h}$ is effective height $(\mathrm{mm})=\mathrm{H}-\mathrm{H}_{\mathrm{r}}, \mathrm{H}$ is side rail height $(\mathrm{mm}), H_{\mathrm{r}}$ is rung height $(25 \mathrm{~mm}), \mathrm{W}$ is ladder width $(\mathrm{mm}), \mathrm{A}$ is cable cross section $\left(\mathrm{mm}^{2}\right), \mathrm{N}$ is maximum cable quantity within ladder cross section, and $\mathrm{m}$ is cable weight per meter $(\mathrm{kg} / \mathrm{m})$.

Once the maximum cable weight is calculated, the greatest total load can be obtained by adding the ladder unit weight to max. cable unit load as Max.load $(\mathrm{N} / \mathrm{mm})=$ Max.Cable load per $\mathrm{mm}(\mathrm{N} / \mathrm{mm})+$ Cable ladder weight $(\mathrm{N} / \mathrm{mm})$

\subsection{Step 4: Conduct Finite Element Analysis}

Finite element analysis (FEA) to find the optimal tray support span is performed by using the commercial software, ANSYS Mechanical Ansys Parametric Design Language (APDL) Product Launcher 2019 R1. The Figures 6 and 7 show the flow diagram for NEMA VE 1 test and IEC 61537 test.

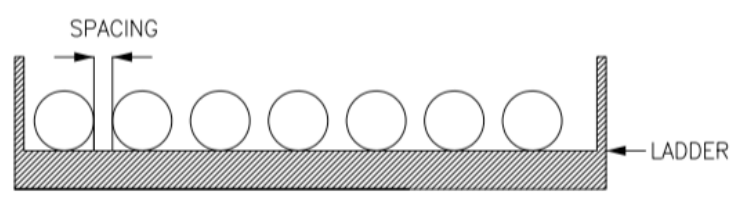

LADDER FOR HIGH VOLTAGE CABLES

Figure 5. The comparison for cable fill allowance 


\section{$\underline{\text { NEMA - Simple Span test }}$}

Geometry modeling \& Meshing

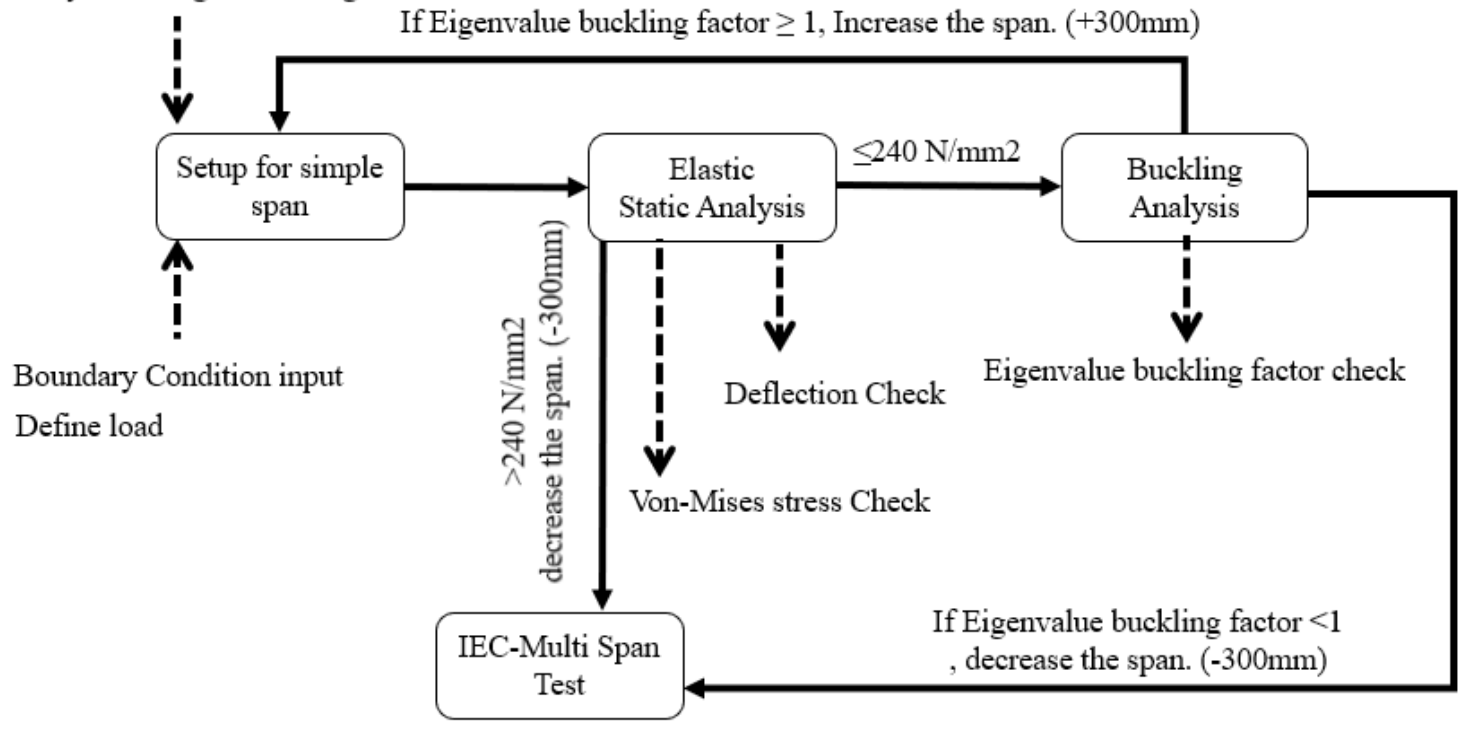

Figure 6. NEMA-Test flow diagram

\section{IEC-Multi Span test}

Geometry modeling \& Meshing If Eigenvalue buckling factor $<1$, decrease the span. $(-300 \mathrm{~mm})$

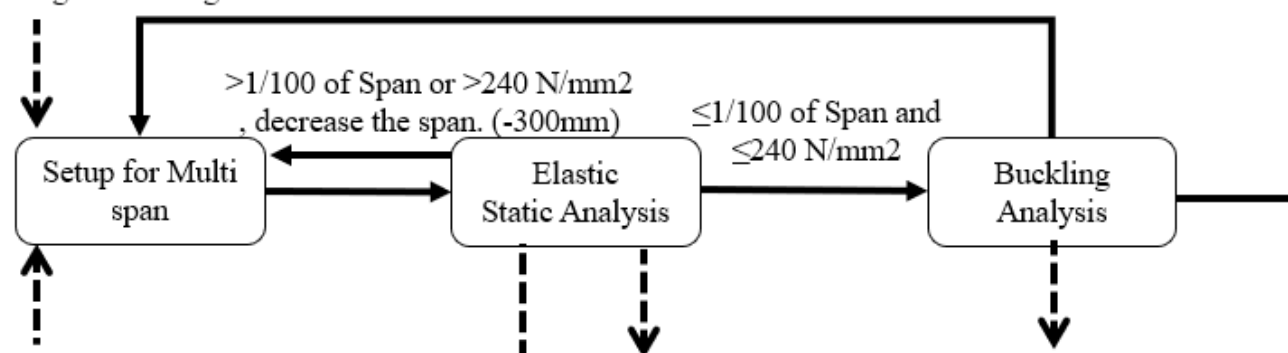

Boundary Condition input

Define load

Deflection Check

Eigenvalue buckling factor check

\footnotetext{
Von-Mises stress Check
}

Finish FEA

If Eigenvalue buckling factor $\geq 1$

Define max. span

Figure 7. IEC-Test flow diagram

\subsubsection{Build the FEA Model}

ANSYS shell elements, "SHELL 181", which is a fournode element with six degrees of freedom at each node, was selected to analyze the stability and the displacement of the ladder when the largest cable load was placed. Figure 8 indicates the direction of the coordinate system.
Modeling for cable ladder was performed based on material property and geometry data shown in Table 2, Table 3 , and Figure 2. For meshing, free mesh is used for this study. On top of that, the splicing modeling is not considered for IEC 61537 deflection test because the bending moment at the position of splicing is as small as negligible when it has been placed on 1/4 of span. 


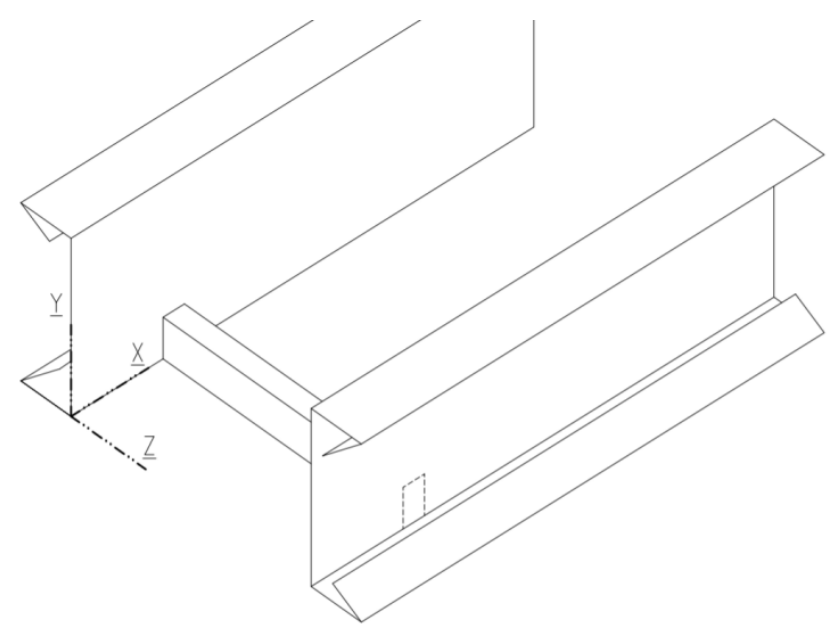

Figure 8. Directions for the coordinate system

\subsubsection{Apply Boundary Conditions and Loads}

The boundary conditions for the round steel bar supports are shown in Figure 9. The midpoints of both webs are restrained in $\mathrm{x}, \mathrm{y}$ and $\mathrm{z}$ direction on the first support and only in y direction on other supports. However, there is no restraint of rotation in all direction.

The unit load is applied to the elements on the top of rung. Since a rung is spaced in every $300 \mathrm{~mm}$, the value of pressure on elements is

$$
\mathrm{P}=\frac{300(\mathrm{~mm}) \times \text { unit load }(\mathrm{N} / \mathrm{mm})}{\text { Rung Area }\left(\mathrm{mm}^{2}\right)}
$$

where

Unit load $=$ (Maximum cable unit load + ladder unit weight $) \times$ Safety factor

and rung area is $900 \mathrm{~mm} \times 41.7 \mathrm{~mm}=37,530 \mathrm{~mm}^{2}$, IEC safety factor $=170 \%$, and NEMA safety factor $=150 \%$.

\subsubsection{Perform the Analysis of Deflection and Stress}

The elastic static analysis is conducted to verify wheth-

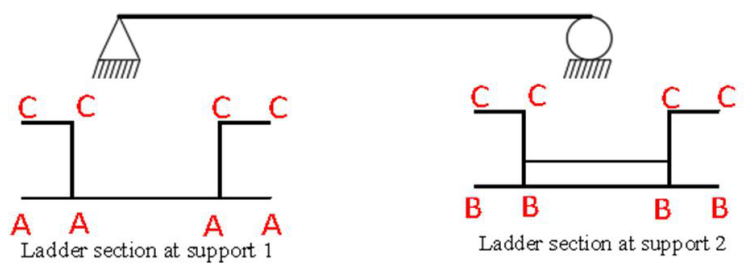

SIMPLE SPAN TEST

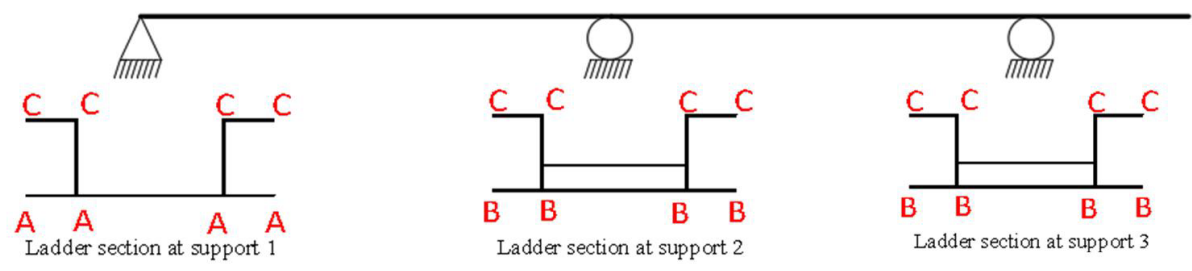

MULTIPLE SPAN TEST

\begin{tabular}{|c|c|c|c|c|c|c|}
\hline Node points & UX & RX & UY & RY & UZ & RZ \\
\hline A & O & & O & & O & \\
\hline B & & & O & & & \\
\hline C & & & & & & \\
\hline
\end{tabular}

Figure 9. Boundary condition for supports 
er the vertical deflection and Von-Mises stress at mid-span do not exceed the criteria in Table 4 when the greatest cable load is placed.

Table 4. The criteria of deflection and stress

\begin{tabular}{ccc}
\hline Test type & Max. deflection at side rail. & $\begin{array}{c}\text { Max Stress (yield } \\
\text { stress) }\end{array}$ \\
\hline $\begin{array}{c}\text { NEMA destruction load } \\
\text { test }\end{array}$ & $\begin{array}{c}\text { NA, } \\
\text { only record for } \\
\text { comparison }\end{array}$ & $<240 \mathrm{MPa}$ \\
IEC deflection load test & $<1 / 100$ of span without & \\
& collapse & $<240 \mathrm{MPa}$ \\
\hline
\end{tabular}

The maximum vertical deflection at mid-span shall be measured at the points near the side. In other words, the rung sagging displacement (transverse sagging) should be excluded in the calculation of the vertical displacement. For accurate measurement of displacement and stress, those values need to be obtained by using "path operation". Figure 10 shows the path of measuring point in ANSYS.

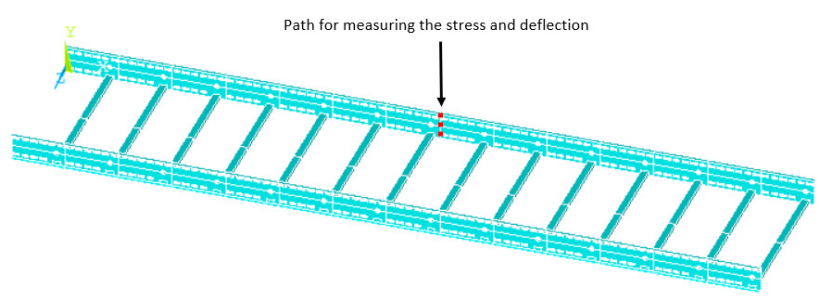

Figure 10. Path for measuring stress and deflection

Table 5 indicates the coordinate of location for "define path" in order to measure the max. stress and max. displacement at mid-span.

\subsubsection{Conduct Eigenvalue Buckling Analysis}

Eigenvalue buckling analysis estimates the theoretical buckling strength of an ideal elastic structure. It predicts the structural eigenvalues for the given conditions such as load and constraints. If the eigenvalue under the largest load condition is less than 1 , the cable ladder will collapse at the placed load. So, when the result is less than 1, the span of support shall be reduced to avoid the buckling of side rail ${ }^{[17]}$.

\subsection{Step 5: Conduct Simplified Hand Calculation}

The maximum vertical sagging displacement and the greatest bending stress at middle of span can be estimated based on following simplified formula.

Assumption:

(1) The material is linear elastic

(2) The side rail is prismatic, which means that cross-section remains constant throughout its length.

Maximum vertical deflection for simple span in Figure 11 is

$\delta=\left|\frac{-\mathrm{wx}\left(\mathrm{L}^{3}-2 \mathrm{Lx}^{2}+\mathrm{x}^{3}\right)}{24 \mathrm{EI}}\right|$

With $\delta_{\max }=\frac{5 \mathrm{wL}^{4}}{384 \mathrm{EI}} \quad$ at $\mathrm{x}=\mathrm{L} / 2$

where $\mathrm{E}$ is Elastic modulus $\left(\mathrm{N} / \mathrm{mm}^{2}\right)$, I is Moment of Inertia of side rail $\left(\mathrm{mm}^{4}\right), \mathrm{L}$ is Support span $(\mathrm{mm}), \mathrm{x}$ is Distance from pin support, $\mathrm{w}$ is Load per unit length $(\mathrm{N} /$ $\mathrm{mm}$ ), and $\delta_{\max }$ is Maximum deflection (mm).

Table 5. The coordinate of location for "define path"

\begin{tabular}{cccccccc}
\hline Test Code & $\begin{array}{c}\text { Span } \\
(\mathbf{m m})\end{array}$ & $\mathbf{X}(\mathbf{m m})$ & $\mathbf{Y}(\mathbf{m m})$ & $\mathbf{Z}(\mathbf{m m})$ & $\mathbf{X}(\mathbf{m m})$ & $\mathbf{Y}(\mathbf{m m})$ & $\mathbf{Z}(\mathbf{m m})$ \\
\hline NEMA VE1 & 3000 & 1500 & 0 & 0 & 1500 & 147 & 0 \\
NEMA VE1 & 3300 & 1650 & 0 & 0 & 1650 & 147 & 0 \\
NEMA VE1 & 3600 & 1800 & 0 & 0 & 1800 & 147 & 0 \\
NEMA VE1 & 3900 & 1950 & 0 & 0 & 1950 & 147 & 0 \\
NEMA VE1 & 4200 & 2100 & 0 & 0 & 2100 & 147 & 0 \\
IEC 61537 & 3900 & $4875[1]$ & 0 & 0 & $4875[1]$ & 147 & 0 \\
\hline
\end{tabular}

Note:

${ }^{[1]}$ Middle position of intermediate span in multiple span test. 


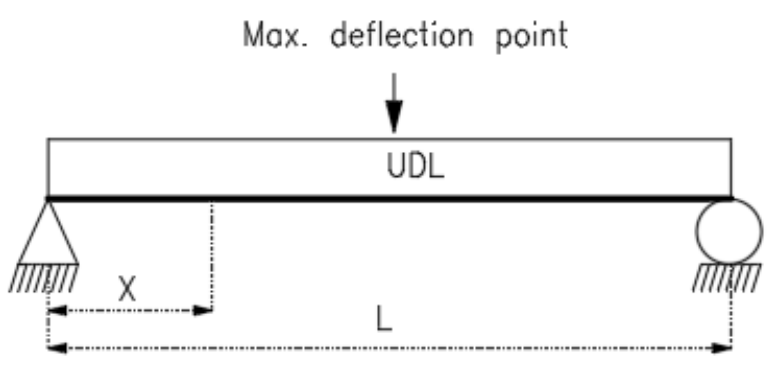

Figure 11. Simple beam with UDL

When cable ladders are installed across several supports with UDL as Figure 12, the maximum sagging displacement is

$\delta_{\max }=\frac{0.0031 \times \mathrm{w} \times \mathrm{L}^{4}}{\mathrm{E} \times \mathrm{I}} \quad$ at mid of intermediate $\operatorname{span}(8)$

where $\mathrm{E}$ is Modulus of elasticity $\left(\mathrm{N} / \mathrm{mm}^{2}\right)$, I is Moment of Inertia of side rail $\left(\mathrm{mm}^{4}\right), \mathrm{w}$ is Load per unit length(N/ $\mathrm{mm}), \mathrm{L}$ is Support span $(\mathrm{mm}), \delta_{\max }$ is Maximum deflection $(\mathrm{mm})$, and $\mathrm{E}$ and I are constant.

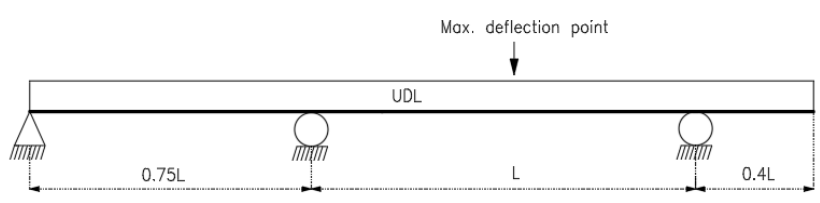

Figure 12. Continuous simply supported beam with overhanging

Maximum bending stress at middle of span is

$\sigma_{\max }=\frac{\mathrm{M}_{\max } \times \mathrm{y}}{\mathrm{I}}$

with

$\mathrm{M}_{\text {max }}=\frac{\mathrm{w} \times \mathrm{L}^{2}}{8}($ in simple span test $)$

$\mathrm{M}_{\max }=0.0455 \times \mathrm{w} \times \mathrm{L}^{2}$ (at intermediate span in multi span test)

where $\mathrm{M}$ is bending moment at the middle of span $(\mathrm{N} \cdot \mathrm{mm}), \mathrm{L}$ is support span $(\mathrm{mm}), \mathrm{w}$ is load per unit length $(\mathrm{N} / \mathrm{mm})$, I is moment of Inertia of side rail $\left(\mathrm{mm}^{4}\right)$, $y$ is vertical distance away from the neutral axis(mm), and $\sigma_{\max }$ is Maximum bending stress at the middle of span $(\mathrm{N} /$ $\mathrm{mm}^{2}$ ).

Figure 13 shows the bending moment diagram for the continuous span of IEC 61537. Bending moment for each position indicated in Figure 13 can be calculated as

M1: zero from left of beam $=0$

M2: $0.27 \times \mathrm{L}$ from left of beam $=0.0364 \times \mathrm{w} \times \mathrm{L}^{2}$

M3: $0.75 \times$ L from left of beam $=-0.079 \times w \times \mathrm{L}^{2}$

M4: $1.25 \times \mathrm{L}$ from left of beam $=0.0455 \times \mathrm{w} \times \mathrm{L}^{2}$
M5: $1.75 \times \mathrm{L}$ from left of beam $=-0.08 \times \mathrm{w} \times \mathrm{L}^{2}$

M6: $2.15 \times \mathrm{L}$ from left of beam $=0$

where $\mathrm{w}$ is load per unit 1 ength $(\mathrm{N} / \mathrm{mm})$ and $\mathrm{L}$ is intermediate span length ( $\mathrm{mm})$.

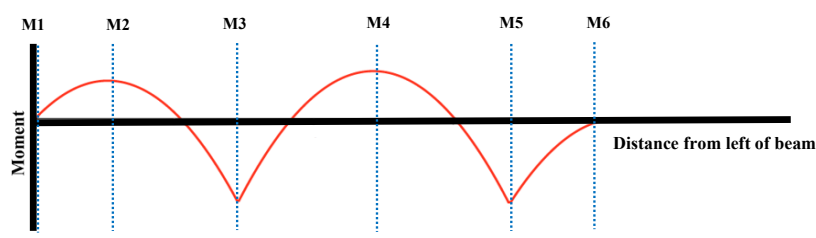

Figure 13. Bending moment diagram for IEC 61537 test

\subsection{Step 6: The Validation of the Result}

The validation of the result is performed in two ways; one is to compare the result of FEA and the result of hand calculation and the other is to verify the constructability for the greatest span obtained from FEA.

The comparison is made for the deflection and bending stress. If the difference between two outputs is too large to be neglectable, the errors shall be corrected until the gaps reach the acceptable range or a justification for the errors shall be addressed.

In addition, it is required to be validated whether the weight of cable ladder is suitable to handle and install at site when the longest span in FEA is applied. In current practice, the cable ladder is manually handled and installed by maximum of two workers. Therefore, the maximum weight of cable ladder shall be less than two times of the maximum recommended weight for manual lifting defined in National Institute for Occupational Safety and Health (NIOSH). In other words, if the ladder weight is more than $46.26 \mathrm{~kg}$, more manpower may be required to handle and install the cable ladder at new span.

$23.13 \mathrm{~kg} \times$ Number of worker( 2 persons $) \geq$ The weight of cable ladder $46.26 \mathrm{~kg} \geq$ The weight of cable laddder

where $23.13 \mathrm{~kg}$ is the maximum recommended weight for manual lifting without injuries in ideal condition ${ }^{[18]}$.

\section{Results}

\subsection{Maximum Load}

Table 6 shows the result of the maximum load calculation. For the finite element analysis and the hand calculation, the safety factor defined in each standard shall be multiplied with the sum of cable weight $\&$ ladder weight.

In this study, only data for width $900 \mathrm{~mm}$ is considered because NEMA VE-1 states the test shall be conducted with the greatest width ${ }^{[14]}$. 
Table 6. The summary of maximum load

\begin{tabular}{|c|c|c|c|c|c|}
\hline $\begin{array}{l}\text { Width of ladder } \\
\qquad[\mathrm{mm}]\end{array}$ & $\begin{array}{l}\text { Max. Cable weight (A) } \\
\qquad[\mathrm{N} / \mathrm{mm}]\end{array}$ & $\begin{array}{l}\text { Ladder weight (B) } \\
\qquad[\mathrm{N} / \mathrm{mm}]\end{array}$ & $\begin{array}{c}\operatorname{Max} \cdot \operatorname{load}(\mathrm{C}) \\
(\mathrm{A})+(\mathrm{B}) \\
{[\mathrm{N} / \mathrm{mm}]}\end{array}$ & $\begin{array}{c}\text { NEMA Test } \\
(\mathrm{C})^{*} 1.5[1] \\
{[\mathrm{N} / \mathrm{mm}]}\end{array}$ & $\begin{array}{c}\text { IEC Test } \\
(\mathrm{C}) * 1.7[2] \\
{[\mathrm{N} / \mathrm{mm}]}\end{array}$ \\
\hline 300 & 0.430 & 0.057 & 0.487 & 0.730 & 0.828 \\
\hline 450 & 0.645 & 0.062 & 0.707 & 1.060 & 1.202 \\
\hline 600 & 0.860 & 0.068 & 0.928 & 1.392 & 1.577 \\
\hline 750 & 1.075 & 0.073 & 1.148 & 1.722 & 1.951 \\
\hline 900 & 1.290 & 0.078 & 1.369 & 2.053 & 2.327 \\
\hline
\end{tabular}

\subsection{Finite Element Analysis}

Numerical analysis has been carried out for both NEMA VE-1 destruction load test and IEC 61537 deflection load test.

\subsubsection{NEMA VE-1 Destruction Load Test}

By using formula (4), the test pressure distributed on the top of each rung has been calculated as

$$
0.0164 \mathrm{~N} / \mathrm{mm}^{2}=\frac{300(\mathrm{~mm}) \times 2.05(\mathrm{~N} / \mathrm{mm})}{37530\left(\mathrm{~mm}^{2}\right)}
$$

The Figure 14 shows the largest vertical deflection (vertical sagging of side rail) which is measured at midspan. It significantly increases as span increases.

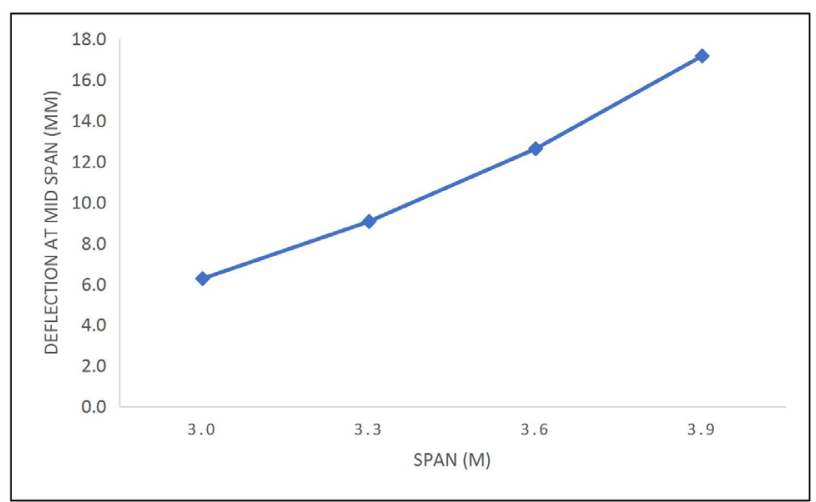

Figure 14. Maximum vertical deflection for simple span

Figure 15 is the trend for Von-Mises stress as span increases. Although the longer the span is, the larger the Von-Mises stress is, the maximum Von-Mises stress at the mid-span did not reach the yield stress of material up to $3.9 \mathrm{~m}$ span.

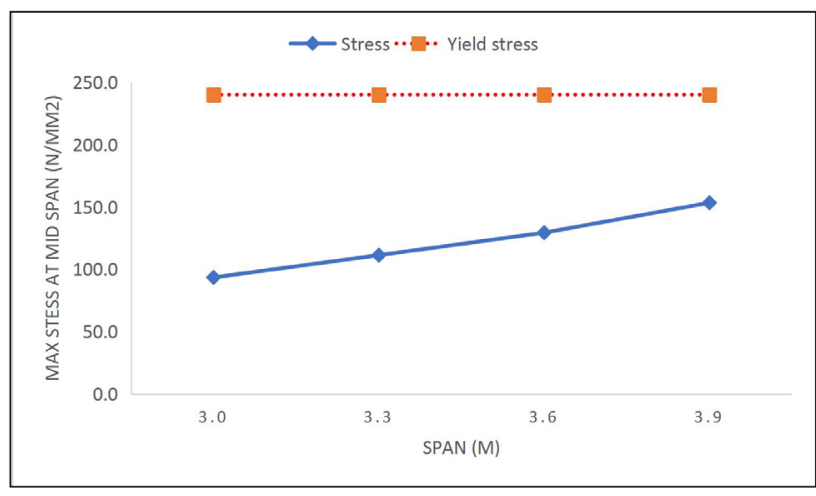

Figure 15. Max. Von-Mises stress for simple span

Based on the stress contour in Figures 16, the largest stress was observed at boundary condition location position of support, but it was neglectable because of the minor area. Other than the stress at boundary condition location, the greatest bending stress was induced on top flange of side rail at mid-span where the largest vertical displacement took place.

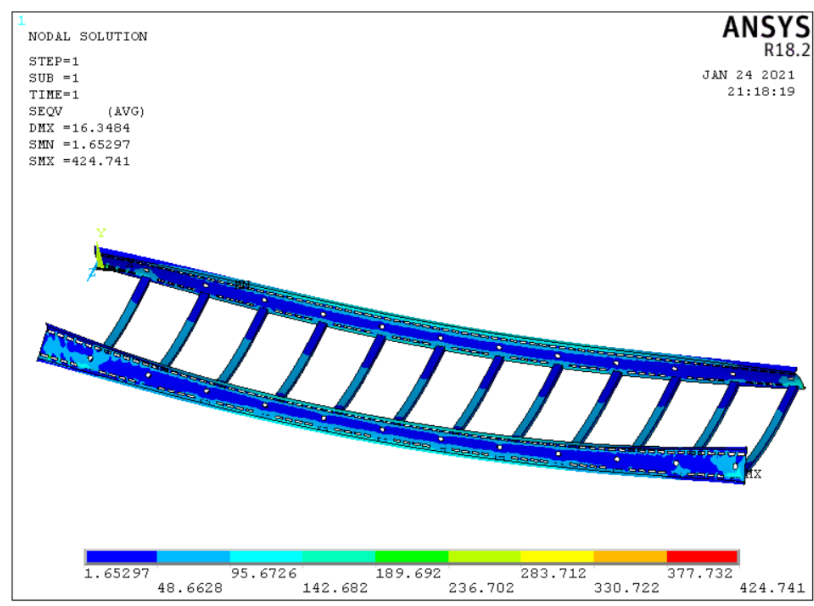

Figure 16. Von-Mises stress contour for NEMA destruction test with $3.6 \mathrm{~m}$ span 
Figure 17 shows the result for eigenvalue buckling analysis when $0.0164 \mathrm{~N} / \mathrm{mm}^{2}$ is uniformly distributed on the top of rung. As a result, the elastic critical bending moment reached between $3.6 \mathrm{~m}$ span and $3.9 \mathrm{~m}$ span because eigenvalue buckling factor in this region became less than 1 . Therefore, it concludes that the largest span of NEMA test simulation is about $3.6 \mathrm{~m}$.

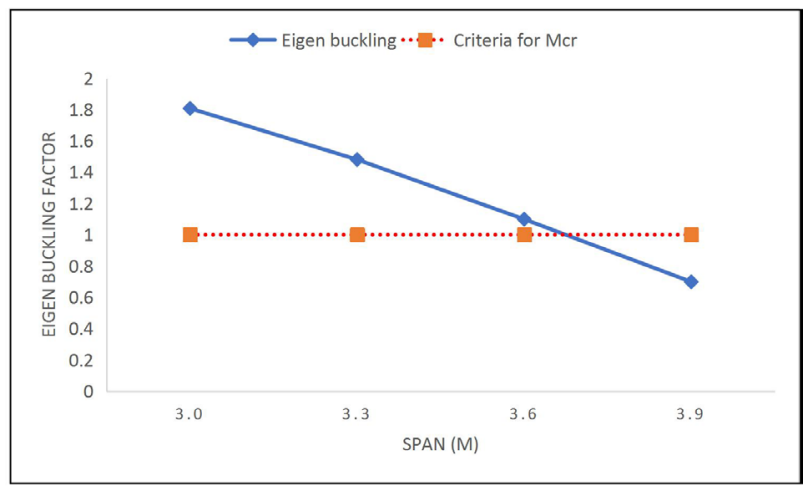

Figure 17. Eigenvalue buckling factor for simple span

\subsubsection{IEC 61537 Deflection Load Test}

The pressure for each rung for deflection load test is:

$$
0.0186 \mathrm{~N} / \mathrm{mm}^{2}=\frac{300(\mathrm{~mm}) \times 2.33(\mathrm{~N} / \mathrm{mm})}{37530\left(\mathrm{~mm}^{2}\right)}
$$

The finite element analysis for IEC 61537 load test was performed only at the longest span $(3.6 \mathrm{~m})$ which met NEMA VE-1. Figure 18 is stress contour for multi-span (IEC 61537) condition. As for simple span (NEMA VE-1 load test), the greatest stress was found at the boundary condition of the support and it is neglectable due to the minor area near hole. Other than the stress at support position, the maximum bending stress occurred on the top flange of side rail at middle of intermediate span where the largest vertical displacement was observed.

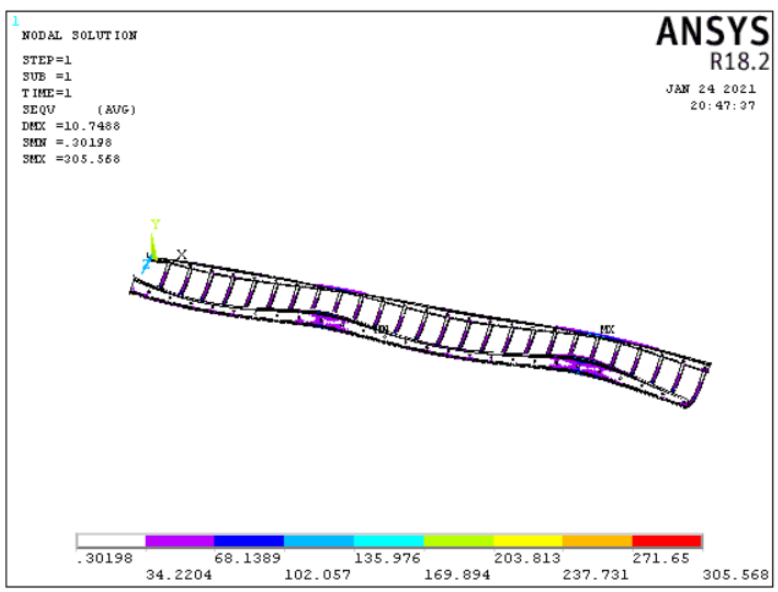

Figure 18. Von-Mises stress Contour for IEC deflection test with $3.6 \mathrm{~m}$ span
Figure 19 is deformed shape of buckling for IEC test. Eigen buckling factor is 2.16 which is almost 2 times of Eigen buckling factor in simple span load test.

FACT $=2.15965$
DMX $=1.00198$ $20: 22: 52$

Figure 19. Deformed shape of buckling for IEC deflection test with $3.6 \mathrm{~m}$ span

Table 7 is comparison of results between NEMA load test (simple span) and IEC load test (multiple span). All outcomes of the multiple span are much more positive than that of simple span.

Table 7. Simple span versus multi-span at $3.6 \mathrm{~m}$ span

\begin{tabular}{|c|c|c|c|c|}
\hline Value & $\begin{array}{l}\text { NEMA-simple } \\
\text { span } \\
\text { (A) }\end{array}$ & $\begin{array}{l}\text { IEC-multi span } \\
\text { (B) }\end{array}$ & Criteria & (A)/(B) \\
\hline $\begin{array}{c}\text { Max. deflection } \\
\text { at mid-span (mm) }\end{array}$ & 12.6 & 2.9 & $\leq 39^{[1]}$ & 4.34 \\
\hline $\begin{array}{l}\text { Max. bending stress } \\
\text { at mid-span }\left(\mathrm{N} / \mathrm{mm}^{2}\right)\end{array}$ & 129.4 & 51.0 & $\leq 240^{[2]}$ & 2.54 \\
\hline $\begin{array}{c}\text { Eigenvalue } \\
\text { buckling factor }\end{array}$ & 1.10 & 2.16 & $\geq 1$ & 0.51 \\
\hline
\end{tabular}

Notes:

[1] $1 / 100$ of $3600 \mathrm{~mm}$

[2] Yield stress of material

In summary, $3.6 \mathrm{~m}$ is the maximum span which doesn't reach critical bending moment for buckling, yield stress and $1 / 100$ of deflection.

\subsection{Simplified Hand Calculation}

The simplified hand calculation has been carried out up to the longest span $(3.6 \mathrm{~m})$ which doesn't reach buckling in numerical analysis. Figures 20 and 21 show the results for the maximum deflection and bending stress at the mid-span. As a result, the vertical deflections of the cable ladder were less than $1 / 100$ of span over whole test span. Moreover, both cases (IEC load test \& NEMA load test) did not reach the yield stress of material. 


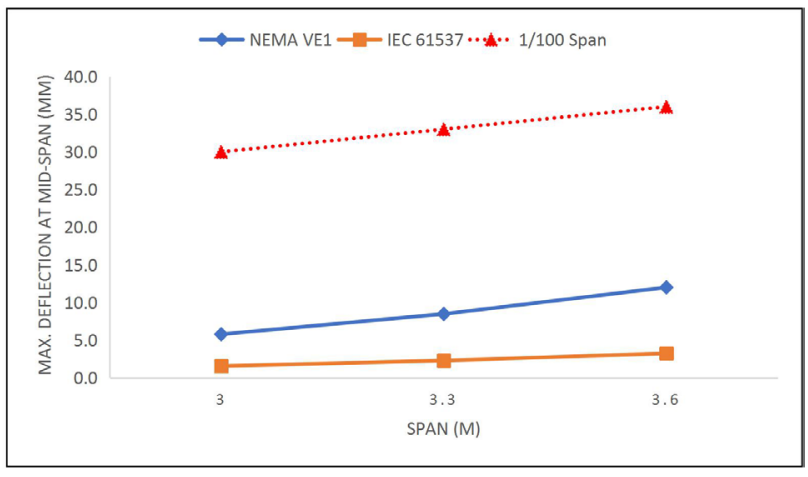

Figure 20. Max. deflection at the middle of span

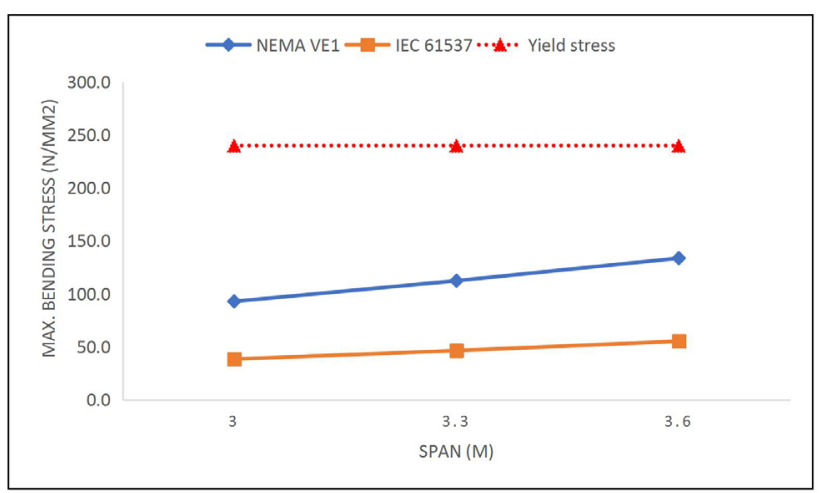

Figure 21. Max. bending stress at the middle of span

\subsection{Comparative Analysis}

As given in Table 8, a comparison is made with the hand calculation results and results obtained from FEA. Overall, the results present a good correlation. The maximum error is about $10 \%$ in the deflection of $3.6 \mathrm{~m}$ span (IEC) and it might occur because not only the effects induced the holes in the web were not considered in simplified hand calculation but also allowing the beam to rotate around the longitudinal axis.

\subsection{Constructability Verification}

The straight length of cable ladder shall be at least equal to the longest span (3.6m) obtained from FEA because more than two splicing units between supports are not allowed ${ }^{[14]}$. In other words, the straight length of cable ladder is not able to be shorter than support span, $3.6 \mathrm{~m}$ in order to minimize its weight

The weight of $3.6 \mathrm{~m}$ cable ladder is

$8 \mathrm{~kg} / \mathrm{m} \times 3.6 \mathrm{~m}=28.8 \mathrm{~kg}$

It concludes the longest span from FEA is acceptable in view of material handling because its weight meets the criteria $(\leq 46.26 \mathrm{~kg})$ in section 2.6 .

\subsection{Case study}

Table 9. Input data for case study ${ }^{[19]}$

\begin{tabular}{ccc}
\hline Data description & Data detail & Remark \\
Project & $\begin{array}{c}\text { A liquified natural gas } \\
\text { terminal facility }\end{array}$ & \\
Supplied cable ladder straight & & \\
section & $\$ 620 \mathrm{~m}$ & cost \\
Support material cost & & \\
Splicing unit material cost (per 1 & $\$ 100 /$ pair ${ }^{[1]}$ & \\
pair) & & \\
Labor rate & & \\
Support installation time & & \\
Cable ladder splicing time & 0.25 hour/pair &
\end{tabular}

Note:

[1] This cost is obtained via personal communication.

To estimate the benefits from the longer support span, a liquified natural gas (LNG) terminal facility project was

Table 8. Hand calculation versus FEA

\begin{tabular}{|c|c|c|c|c|c|c|}
\hline \multirow{2}{*}{$\begin{array}{c}\text { Span } \\
\text { (m) }\end{array}$} & \multicolumn{3}{|c|}{$\begin{array}{l}\text { Max deflection at mid-span } \\
\qquad(\mathrm{mm})\end{array}$} & \multicolumn{3}{|c|}{ Max bending stress at mid-span $\left(\mathrm{N} / \mathrm{mm}^{2}\right)$} \\
\hline & Hand Cal.(A) & FEA(B) & (A)/(B) & Hand Cal.(C) & FEA(D) & (C)/(D) \\
\hline 3(NEMA) & 5.8 & 6.3 & 0.93 & 92.8 & 93.5 & 0.99 \\
\hline 3.3(NEMA) & 8.5 & 9.1 & 0.94 & 112.3 & 111.4 & 1.01 \\
\hline 3.6(NEMA) & 12.0 & 12.6 & 0.95 & 133.6 & 129.4 & 1.03 \\
\hline 3.9(NEMA) & 16.5 & 17.2 & 0.96 & 156.8 & 153.4 & 1.02 \\
\hline 3.6 (IEC) & 3.2 & 2.9 & 1.10 & 55.1 & 51 & 1.08 \\
\hline
\end{tabular}


selected for the case study. This LNG facility had been built by using B-line's products and all required information for the case study is available in the paper generated by B-line. This study explains what kinds of benefits compared to the design based on $3 \mathrm{~m}$ span can be obtained by utilizing $3.6 \mathrm{~m}$ support span which is quite feasible in view of constructability.

The case study was carried out as following steps.

Step 1: To define the input data for case study.

The information from B-line's LNG facility project was used for the case study. Table 9 shows the input data to evaluate the economic impacts of longer span.

Step 2: To estimate the reduced quantity of support.

According to B-line's bill of material for target project, total $7620 \mathrm{~m}$ cable ladder straight section had been supplied. By using total length of cable ladder straight section, minimum required support quantity for each span can be calculated as

Minimum support Qty $(\mathrm{ea})=$

Total length of cable ladder straight section(m) Support $\operatorname{span}(\mathrm{m} / \mathrm{ea})$

where

$$
\text { Total support for } 3 \mathrm{~m} \text { span: } 2540 \mathrm{ea}=\frac{7620 \mathrm{~m}}{3 \mathrm{~m} / \mathrm{ea}}
$$

Total support for $3.6 \mathrm{~m}$ span: $2117 \mathrm{ea}=\frac{7620 \mathrm{~m}}{3.6 \mathrm{~m} / \mathrm{ea}}$

As a result, total 423ea structural steel support for cable ladder straight section can be roughly reduced by changing the support span from $3 \mathrm{~m}$ to $3.6 \mathrm{~m}$.

Step 3: To calculate the positive cost impacts for support material.

The cost for 423ea steel structural support is:

\section{Support material cost savings(\$)}

\section{$=$ Saved support Qty $(\mathrm{ea}) \times$ Unit price for}

$$
\text { support (\$/ea) }
$$

$$
42,300(\$)=423(\text { ea }) \times 100(\$ / \text { ea })
$$

Step 4 To evaluate the cost savings for splicing unit.

The splicing units of cable ladder are demonstrated in Figure 22. The splicing units are used for connecting the two pieces of cable ladder straight section. In general, one pair splicing unit is required for each support span length because cable ladder straight section length is equal to support span length to minimize its weight. Thus, reduced splicing unit quantity is same as the saved support quantity.

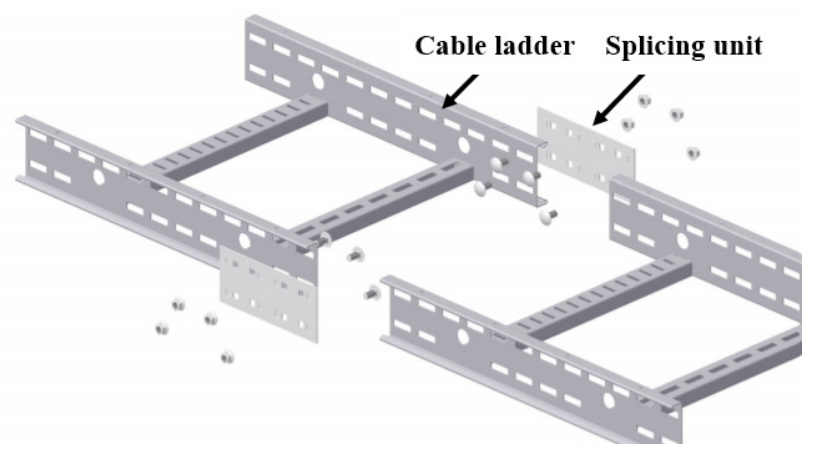

Figure 22. Splicing unit for cable ladder ${ }^{[13]}$

Splicing unit material coat savings $(\$)$

$=$ Reduced splicing unit Qty(pair)

$\times$ Unit price of splicing unit (\$/pair)

$4,230(\$)=423($ ea $) \times 10(\$ /$ ea $)$

Step 5 To obtain the labor cost savings for cable ladder support installation.

Labor cost savings for cable ladder support installation are:

$=$ Labor rate $(\$ /$ hour $) \times$ Manhour for installation(hour $/$ ea $)$

$\times$ Saved support Qty (ea)

$152,280(\$)=60(\$ /$ hour $) \times 0.25$ (hour/pair $) \times 423$ (pair)

Step 6 To get the labor cost decrease for cable ladder splicing.

The labor cost impacts for cable ladder splicing can be calculated as below:

$=$ Labor rate $(\$ /$ hour $) \times$ Manhour for splicing(hour/pair)

$\times$ Reduced splicing unit Qty(pair)

$6,345(\$)=60(\$ /$ hour $) \times 0.25$ (hour $/$ pair $) \times 423$ (pair)

Step 7 To summarize the benefits of new span.

Total economic benefits by employing optimal span, $3.6 \mathrm{~m}$ are summarized in Table 10. Compared to $3 \mathrm{~m}$ support span design, about $205,155 \$$ can be lower by utilizing the $3.6 \mathrm{~m}$ support span.

Table 10. Summary of cost savings

\begin{tabular}{cc}
\hline Description & Cost savings (\$) \\
\hline Cable ladder support material & 42,300 \\
Splicing unit material & 4,230 \\
Labor cost for support installation & 15,2280 \\
Labor cost for cable ladder splicing & 6,345 \\
Total cost savings & 205,155 \\
\hline
\end{tabular}

\section{Discussions}

In cable ladder system design, although the cable 
weight is a chief factor to determine the support span, the method to calculate maximum cable load had not been well defined in earlier research studies. By using the formula derived in this research, the maximum cable weight to be installed on the ladder can be estimated.

The cable ladder which is a kind of slender steel beam might fail due to lateral torsional buckling before yielding the plastic hinge. Through FEA, the greatest span has been estimated as $3.6 \mathrm{~m}$ when the $\mathrm{C}$ channel side rail in Figure 2 is applied. Compared to the span length of offshore practice, it makes $20 \%$ improvement without increasing the cross-section of cable ladder and contributes to reduce the overall ladder system cost such as material cost, labor cost and others.

In view of constructability, the weight of $3.6 \mathrm{~m}$ straight ladder is suitable for manual handling and installation and it is able to give more attractive results when it is applied to the larger project that the proportion in the straight run of cable ladder is greater.

Although there were some approaches to extend the span by increasing the thickness of side rail, it might be a big challenge in view of constructability. For instance, it not only causes the difficulty of material handling because of getting much heavier but also increases the risk of injury during the installation of heavier ladder.

Finally, although the optimal span in this study does not give the large cost saving in view of total project cost, it can be one of contributions to save offshore oil and gas project cost.

\section{Conclusions}

The findings from this study can be summarized as:

According to data from previous projects, the dominated maximum cable ladder support span is $3 \mathrm{~m}$. Both NEMA VE-1 and IEC 61537 are the mainly used standards to determine the largest support span in offshore oil and gas industry. However, there is no well-defined guidance to estimate the greatest cable weight which can be filled on the cable ladder.

On top of that, the formulas in the structural steel design standard such as CAN/CSA S16-14, Eurocode 3 are difficult to be used to get the critical bending moment of cable ladder due to its geometry partially restrained by rung.

(1)According to NEC, control cables can be filled much more in cross section of cable ladder compared to power cables because they do not cause the heat generation problem. Therefore, the largest cable weight which can be calculated by assuming $50 \%$ of fill area of cable ladder is fully filled with the control cables.

(2)Based on the side rail geometry frequently used in offshore industry, FEA has been conducted to find the longest span which meet both NEMA VE-1 and IEC 61537. As a result, optimal span is $3.6 \mathrm{~m}$ which is $0.6 \mathrm{~m}$ longer compared to the offshore typical practice. Moreover, the weight of cable ladder for new span is still suitable for material handling without additional manpower.

(3)When a longer span was applied to a liquefied natural gas terminal facility as case study, about $17 \%$ cost saving could be obtained for cable ladder support system. Although the proportion of cable ladder support system in the cost of the project is small, it can be one of the contributions to save offshore oil and gas project cost.

\section{References}

[1] Sieminski, A. International energy outlook. Energy information administration (EIA), 2014, 18.

[2] IOSS. IOSS Introduction [Online], 2015. Available: https://ioss.info/page/index.php [Accessed].

[3] Ekstrom, C. M., Wesley, D. Lateral-torsional Buckling of Steel Channel Beams. Division of Structural Engineering Chalmers University Of Technology Gothenburg, 2017.

[4] Kalupa, C.J. Guide for design of electrical cable tray systems[J]. IEEE Transactions on Industry Applications, 1977, 6: 533-538.

[5] Desmond, T.P., Dermitzakis, S.N. Effective-length factors for buckling of cable-tray supports[J]. Nuclear Engineering and Design, 1987, 103(3): 313-332.

[6] Reigles, D.G., Brachmann, I., Johnson, W.H., Gürbüz, O. Test-based approach to cable tray support system analysis and design: Behavior and test methods[J]. Nuclear Engineering and Design, 2016, 302: 27-36.

[7] Masoni, P., Pasquale, G.A., Mazzieri, C., Morgana, A. Seismic tests of cable tray systems, 1989.

[8] Huang, B., Lu, W., Mosalam, K.M. Shaking table tests of the cable tray system in nuclear power plants[J]. Journal of Performance of Constructed Facilities, 2017, 31(4): 04017018.

[9] Khalid, M., Baofeng, H. Performance-based Earthquake Engineering Methodology For Seismic Evaluation Of Cable Tray Systems For Nuclear Power Plants, 2019.

[10] De Normalisation, C. E. ENV 1993-1-1 Eurocode 3, design of steel structures, Part 1.1-General rules and rules for buildings. European Committee for Standardization, Brussels, Belgium, 1993.

[11] EN, B. 10088-1: 2005, Stainless Steels-Part1: List of stainless steels. CEN, 2005.

[12] EN, B. 10088-2: 2014. Stainless steels: technical delivery conditions for sheet/plate and strip of corro- 
sion resisting steels for general purposes, 2014.

[13] Oglaend. Oglaend system product [Online]. $2020 \mathrm{~b}$. Available:

https://www.oglaend-system.com/selector/ [Accessed].

[14] NEMA. NEMA VE 1-2017 Metal Cable Tray Systems. National Electrical Manufacturers Association, 2017.

[15] Commission, I. I. E. IEC 61537: Cable managementCable tray systems and cable ladder systems. Geneva (Switzerland): International Electrotechnical Commission, 2016.

[16] Association, N. F. P. NFPA 70: National Electrical Code, National Fire Protection Assoc, 2011.
[17] University of Alberta. Buckling [Online], 2020. Available:

https://sites.ualberta.ca/ wmoussa/AnsysTutorial/IT/ Buckling/Buckling.html [Accessed].

[18] Waters, T. R., Putz-Anderson, V., Garg, A. Applications manual for the revised NIOSH lifting equation, 1994.

[19] B-Line. Cost saving calculator [Online], 2020a. Available:

https://www.eaton.com/content/dam/eaton/products/support-systems/cable-management/structural-steel-savings/structural-steel-savings-engineering-guide-brochure.pdf [Accessed]. 